\title{
Efeito da concentração de fibra e parâmetros operacionais de extrusão sobre as propriedades de pasta de misturas de fécula de mandioca e polpa cítrica
}

\author{
Effect of the fiber content and operational extrusion parameters on the \\ pasting characteristics of cassava starch and orange pulp mixture
}

Luciana Bronzi de SOUZA ${ }^{1}$, Magali LEONEL ${ }^{2 *}$

\section{Resumo}

Para preencher as várias demandas para funcionalidades em produtos alimentícios, a fécula de mandioca misturada à polpa de laranja desidratada foi extrusada sob diferentes condições ( 0 a $20 \%$ de fibras na mistura); (14,6 a $21,4 \%$ de umidade) e $\left(60,8\right.$ a $\left.129^{\circ} \mathrm{C}\right)$ de temperatura de extrusão, objetivando o uso em produtos instantâneos ricos em fibras. A rotação da rosca foi mantida constante em $272 \mathrm{rpm}$, a abertura da matriz foi $3 \mathrm{~mm}$, a taxa de compressão da rosca foi 3:1 e a taxa de alimentação foi de $150 \mathrm{~g} / \mathrm{minuto}$. Os produtos extrusados moídos foram analisados para as propriedades de pasta: viscosidade inicial, pico de viscosidade, quebra de viscosidade, viscosidade final e tendência à retrogradação no Rapid Visco Analyser (RVA), tendo em vista a importância destes parâmetros para este tipo de utilização. Os resultados obtidos mostraram que a porcentagem de fibras foi o parâmetro de maior influência nas propriedades de pasta, e que nas condições de baixo teor de fibras, elevada temperatura e baixa umidade pode ter ocorrido degradação acentuada do amido e solubilização das fibras, levando à redução dos parâmetros de viscosidade.

Palavras-chave: extrusão; laranja; mandioca; viscosidade.

\begin{abstract}
Due the various demands for processed foods with functional ingredients, a mixture of cassava starch and dried orange pulp was extruded under different conditions ( 0 to $20 \%$ of fibers in the mixture); (14.6 to $21.4 \%$ moisture); and $\left(60.8\right.$ to $129^{\circ} \mathrm{C}$ temperature of extrusion) aiming at the use in high fiber instant products. The screw speed was kept constant ( $272 \mathrm{rpm})$, the diameter of die was $3 \mathrm{~mm}$, the compression ratio was $3: 1$, and the feed rate was $150 \mathrm{~g} /$ minute. The following pasting properties of the extruded products were analyzed: initial viscosity, peak of viscosity, breakdown, final viscosity, and retrogradation tendency using a Rapid Visco Analyser (RVA) in view of the importance of these parameters for such use. The results showed that the percentage of fibers was the greatest variable of influence on the pasting characteristics. The conditions of low-fibre, high temperature, and low humidity may have promoted sharp degradation of starch and fiber solubilization leading to the reduction in the viscosity parameters values.

Keywords: extrusion; orange; cassava; viscosity.
\end{abstract}

\section{Introdução}

$\mathrm{O}$ interesse nutricional em fibra dietética coincide com o desenvolvimento e melhora da recuperação da fibra industrializada. Produtos que eram descartados ou usados para alimentação animal, por exemplo, os subprodutos industriais, são hoje em dia largamente aplicados em alimentos (MENDONÇA; GROSSMAN; VERBÉ, 2000).

A fibra alimentar tem cada qual efeito fisiológico diferente. Em geral, as fibras solúveis em água (pectinas, gomas, mucilagens e certas hemiceluloses) retardam a passagem intestinal, o esvaziamento gástrico e a absorção da glicose, ajudando a reduzir o colesterol no soro sanguíneo. As fibras insolúveis em água (lignina, celulose e algumas hemiceluloses) aceleram o trânsito intestinal, aumentam o peso das fezes, desaceleram a hidrólise do amido e retardam a absorção da glicose, contribuindo para a redução do risco de alguns males do cólon (LEONEL; CEREDA; ROAU, 1999).
Apesar de a laranja ser uma fruta muito consumida ao natural pelos brasileiros, é necessário ressaltar que seu destino principal é o esmagamento para produção de suco concentrado e congelado, o qual o país exporta desde a década de 1960 (INSTITUTO..., 2006).

O suco é o principal produto da laranja, entretanto, vários subprodutos com valor comercial são obtidos durante o seu processo de fabricação. Entre esses subprodutos estão óleos essenciais, d'Limonene, terpenos, líquidos aromáticos, polpa cítrica e o farelo. Eles possuem diferentes aplicações no mercado interno e externo, as quais incluem fabricação de produtos químicos e solventes, aromas e fragrâncias, substâncias para aplicação em indústrias de tintas, cosméticos, complemento para ração animal, entre outros (ARÊAS, 1994).

O rendimento médio dos subprodutos da laranja é de $44,81 \%$ de suco concentrado, $2,67 \%$ de células congeladas, $1,79 \%$ óleos

Recebido para publicação em 4/6/2008

Aceito para publicação em 21/6/2009 (003554)

${ }^{1}$ Nutrição-IB, Universidade Estadual Paulista - UNESP, Botucatu - SP, Brasil

${ }^{2}$ Centro de Raízes e Amidos Tropical, Universidade Estadual Paulista - UNESP, CP 237, CEP 18603-970, Botucatu - SP, Brasil, E-mail: mleonel@fca.unesp.br

${ }^{*}$ A quem a correspondência deve ser enviada 
essências, 0,92\% d'Limonene, 0,57\% líquidos aromáticos e 49,24\% de farelo (ASSOCIAÇÃO..., 2009).

A polpa de laranja é composta pelas vesículas que armazenam o suco e pelas membranas que separam estas vesículas em gomos. De acordo com Chau e Huang (2003) a laranja apresenta 57,0\% de fibra alimentar total, com $9,4 \%$ de fibra solúvel e $47,6 \%$ de fibra insolúvel. Boekel, Pumar e Freitas (2002), caracterizando albedo e polpa de laranja, visando o uso como fonte de fibra alimentar, obtiveram teores de 57,36\% de fibra total, 14,04\% de fibra solúvel e 43,29\% de fibra insolúvel. Santana (2005), realizando a caracterização físico-química da fibra alimentar de laranja, encontrou 76,5; 61,15 e 90,32\% de fibra total no albedo, vesículas de suco e membrana carpelar, respectivamente, sendo que destes 60,02; 55,17 e 72,73\% eram fibras insolúveis e 16,02; 5,98 e 17,59\% eram fibras solúveis em cada material analisado.

A fécula de mandioca é um produto de mercado mundial crescente, sendo a Tailândia o maior produtor. Com a adição das produções da Indonésia, China e Brasil, com mais de 500.000 toneladas cada, além da produção de outros países de menor importância, tais como a Índia, com pouco mais de 300.000 toneladas, a produção mundial de fécula de mandioca supera 4 milhões de toneladas (INSTITUTO..., 2006).

Uma tecnologia que tem sido muito utilizada pelas indústrias no desenvolvimento de produtos é a extrusão. O princípio fundamental do processo de extrusão é converter um material sólido em um fluido por aplicação de calor e trabalho mecânico e extrusá-lo através de uma matriz, promovendo assim sua termoplastificação (CHANG et al., 2001).

O amido extrusado, de acordo com as condições do processo, sofre transformações químicas que causam intumescimento e ruptura dos grânulos, modificações das estruturas cristalinas, provocando solubilidade e viscosidade em água fria. Estas alterações estão relacionadas com o maior ou menor grau de gelatinização e dextrinização do amido, interferindo em suas propriedades físicas (EL-DASH; GONZALES; CIOL, 1984; CHEFTEL, 1986).

Durante a extrusão pode ocorrer à solubilização da fibra de algumas fontes alimentares, dependendo da severidade do processo (alta temperatura, alta velocidade do parafuso e baixo teor de umidade) (ASCHERI et al., 2006). De acordo com Guy (2001), em condições brandas ou moderadamente severas de processamento por extrusão, não há mudanças no teor de fibra total de forma significativa.

A viscosidade de pasta do amido, avaliada em viscosímetro, parece ser determinada por dois fatores: o grau de inchamento dos grânulos e a resistência desses grânulos à dissolução pelo calor ou a fragmentação pela agitação mecânica (EL-DASH; GONZALES; CIOL, 1984). A viscosidade inicial dos amidos é praticamente nula. Ao realizar tratamento térmico por extrusão, o amido gelatiniza, absorve água a frio e, quanto maior o grau de gelatinização, maior será a capacidade de formar uma pasta, gel ou líquido viscoso à temperatura ambiente (FRANCO et al., 2001). Esta modificação permite a obtenção de produtos amiláceos instantâneos, como sopas, massas e alimentos infantis.

Devido às modificações que sofrem os produtos amiláceos e as fibras após o processo de extrusão, estudos que avaliem o efeito das condições operacionais sobre as propriedades de pasta são de grande importância para o desenvolvimento de novos produtos.

Nesta linha, este trabalho teve por objetivo avaliar o efeito da porcentagem de fibra dietética na mistura de fécula de mandioca e polpa cítrica, umidade e temperatura de extrusão sobre as propriedades de pasta das misturas extrusadas, visando uma possível aplicação destes resultados no desenvolvimento de produtos instantâneos à base de fécula de mandioca e polpa cítrica desidratada.

\section{Material e métodos}

A fécula de mandioca foi obtida na empresa Halotek-Fadel Industrial Ltda., localizada na cidade de Palmital - SP. A polpa cítrica úmida foi obtida na Usina Nova América S/A, situada em Santa Cruz do Rio Pardo - SP. As matérias-primas foram analisadas quanto ao teor de umidade, proteína, fibras, cinzas, matéria-graxa, açúcares totais e amido (fécula) (AMERICAN..., 1983).

O teor de fibra dietética na polpa cítrica desidratada foi determinado de acordo com o proposto por Asp et al. (1983), que utiliza enzimas e são obtidas as frações de fibra solúvel e insolúvel presentes nas amostras, sendo a soma o teor de fibra total.

Após a caracterização das matérias-primas, as amostras foram condicionadas para a obtenção de diferentes teores de fibras na mistura de fécula de mandioca e polpa cítrica, conforme o delineamento experimental (Tabela 1).

O condicionamento das amostras para os diferentes níveis de umidade foi realizado com água destilada adicionada lentamente com pipeta. A quantidade de água adicionada às amostras foi calculada pela Equação 1:

$\mathrm{Y}=(\mathrm{Uf}-\mathrm{Ui}) \times \mathrm{Pa} / 100-\mathrm{Uf}$

em que: $\mathrm{Y}=$ quantidade de água a ser adicionada $(\mathrm{mL})$; Uf = Umidade Final da amostra; Ui = Umidade Inicial da amostra; $\mathrm{Pa}=$ Peso da amostra (g).

O processo de extrusão foi realizado em linha de extrusão IMBRA RX da Inbramaq - Indústria Brasileira de Máquinas Ltda., com rosca simples e capacidade de produção de $45 \mathrm{~kg} /$ hora, e teve como parâmetros fixos do processo:

- Taxa de compressão da rosca (4,5 mm profundidade e $14 \mathrm{~mm}$ de largura);

- Taxa de alimentação (g/min ): $150 \mathrm{~g} / \mathrm{min}$;

- Abertura da matriz (mm): $3 \mathrm{~mm}$;

- Temperatura na $1^{\mathrm{a}}$ zona e $2^{\mathrm{a}}$ zona: 25 e $60^{\circ} \mathrm{C}$; e

Tabela 1. Parâmetros variáveis do processo de extrusão.

\begin{tabular}{cccccc}
\hline \multicolumn{2}{c}{ Níveis } & & \multicolumn{3}{c}{ Fatores ou variáveis independentes } \\
\cline { 1 - 2 } \cline { 4 - 6 } Axiais & Codificados & & $\mathrm{F}$ & $\mathrm{T}$ & $\mathrm{U}$ \\
\hline$-\alpha$ & $-1,682$ & & 0 & 60,8 & 14,6 \\
& -1 & & & 75 & 16 \\
& 0 & 10 & 95 & 18 \\
& +1 & 16 & 115 & 20 \\
$+\alpha$ & $+1,682$ & & 20 & 129 & 21,4 \\
\hline $\mathrm{F}=$ porcentagem de fibras dietéticas na mistura (\%); $\mathrm{T}=$ temperatura de extrusão $\left({ }^{\circ} \mathrm{C}\right) ;$ \\
$\mathrm{U}=$ umidade (\%).
\end{tabular}


- Rotação da rosca: 272 rpm.

Foram consideradas como variáveis independentes no processo: a temperatura na terceira zona de aquecimento do canhão de extrusão, a umidade das misturas e a porcentagem de fibras (Tabela 1).

Para analisar o efeito combinado das variáveis independentes nas características tecnológicas dos extrusados, foi utilizado o delineamento 'central composto rotacional' para três fatores, com um total de 15 tratamentos (COCHRAN; COX, 1957), a saber:

- Oito tratamentos correspondentes ao fatorial $2^{3}$, onde os três fatores são:

- $\mathrm{F}=$ porcentagem de fibras $(\%), \mathrm{T}=$ temperatura na $3^{\mathrm{a}}$ zona de aquecimento $\left({ }^{\circ} \mathrm{C}\right)$ e $\mathrm{U}=$ umidade da mistura (\%), cada qual em dois níveis, codificados como -1 e +1 ;

- Seis tratamentos com os níveis mínimo e máximo de cada fator, codificados como $-\alpha \mathrm{e}+\alpha$, respectivamente, sendo $\alpha=2^{3 / 4}=1,682 ; \mathrm{e}$

- Um tratamento central repetido 6 vezes, onde os fatores estão todos em um nível médio, codificado como zero (Tabela 1).

Para a análise das propriedades de pasta, foi utilizado o Rapid Visco Analyser (RVA). As suspensões de amido (3,5 g de amostra em $25 \mathrm{~mL}$ de água), corrigidas para a base de 14\% de umidade.

Foi utilizada a programação Extrusion 2 para as amostras extrusadas, do software Thermocline for Windows, versão 2.2. As amostras passaram pela programação apresentada na Tabela 2.

Do gráfico obtido foram avaliadas as seguintes características: Viscosidade Inicial (VI), que é o pico de viscosidade entre o tempo 0,2 e 2 minutos; Pico de Viscosidade (PV), que é a viscosidade máxima obtida após o início do aquecimento e antes do resfriamento; Queda de Viscosidade (QV), que é a diferença entre a viscosidade máxima e a viscosidade da pasta mantida a $95^{\circ} \mathrm{C}$ (hold); Tendência à Retrogradação (TR), que é a diferença entre a viscosidade final e o menor valor de viscosidade durante a manutenção a $95^{\circ} \mathrm{C}$ (hold) e a Viscosidade Final (VF).

A Metodologia de Superfície de Resposta descreve o comportamento de um sistema no qual estão combinadas as variáveis independentes $\left(\mathrm{X}_{\mathrm{k}}\right)$ e a variável dependente ou resposta $\left(\mathrm{Y}_{\mathrm{i}}\right)$. A resposta é uma função dos níveis nos quais estes fatores foram combinados e definidos.

Tabela 2. Programa Extrusion 2 utilizado na análise das propriedades de pasta dos produtos extrusados (NEWPORT SCIENTIFIC, 1998).

\begin{tabular}{clc}
\hline Tempo & \multicolumn{1}{c}{ Tipo } & Valor \\
\hline 00:00:00 & Temperatura & $25^{\circ} \mathrm{C}$ \\
00:00:00 & Velocidade de rotação & $960 \mathrm{rpm}$ \\
00:00:10 & Velocidade de rotação & $160 \mathrm{rpm}$ \\
00:02:00 & Temperatura & $25^{\circ} \mathrm{C}$ \\
00:07:00 & Temperatura & $90^{\circ} \mathrm{C}$ \\
$00: 10: 00$ & Temperatura & $90^{\circ} \mathrm{C}$ \\
$00: 15: 00$ & Temperatura & $25^{\circ} \mathrm{C}$ \\
\hline
\end{tabular}

Dentro das faixas de variação propostas, ou seja, dentro da região caracterizada por esses níveis, o comportamento de cada resposta pode ser predito de forma generalizada de acordo com a Equação 2:

$Y_{1}=\beta_{0}+\beta_{1} X_{1}+\beta_{2} X_{2}+\beta_{3} X_{3}+\beta_{11} X_{1}^{2}+\beta_{22} X_{2}^{2}+\beta_{33} X_{3}^{2}+$

$\beta_{12} X_{1} X_{2}+\beta_{13} X_{1} X_{3}++\beta_{23} X_{2} X_{3}+\varepsilon$

em que: $Y_{1}=$ variável dependente ou função resposta; $X_{1}, X_{2}, X_{3}=$ valores das variáveis independentes; $\beta_{\mathrm{o}}=$ coeficiente relativo à interceptação do plano com o eixo resposta; $\beta_{1}, \beta_{2} \beta_{3}=$ coeficientes lineares estimados pelo método dos mínimos quadrados; $\beta_{11}, \beta_{22}, \beta_{33}=$ coeficientes das variáveis quadráticas; $\beta_{12}, \beta_{13}, \beta_{23}=$ coeficientes de interação entre as variáveis independentes; $\varepsilon=$ erro experimental.

$\mathrm{O}$ ajuste do modelo foi feito pela opção step-wise do programa SAS, sendo que o modelo obtido foi validado pelo teste $F$, utilizando-se como denominador o quadrado médio do erro puro.

As superfícies de resposta foram construídas utilizando-se o software STATISTICA versão 5.5. Na construção das superfícies, uma das variáveis independentes foi mantida fixa no ponto central, enquanto que as outras duas variaram dentro das regiões propostas no planejamento.

\section{Resultados e discussão}

\subsection{Caracterização das matérias-primas}

Dentre os fatores que interferem na qualidade de produtos extrusados a composição da matéria-prima e as condições de operação do extrusor estão entre os de maior influência.

Os resultados obtidos nas análises de composição química da fécula de mandioca comercial e da polpa cítrica desidratada estão apresentados na Tabela 3.

A fécula de mandioca apresentou-se como matéria-prima com elevado teor de amido e baixas quantidades de componentes não amido, o que é característica desse produto comercial. Os resultados obtidos mostraram que a composição centesimal da fécula encontra-se dentro dos limites estabelecidos pela legislação brasileira, que determina: máximo de 14\% de umidade, mínimo de $80 \%$ de amido, máximo de $0,50 \%$ de

Tabela 3. Composição química da fécula de mandioca e da polpa de laranja desidratada.

\begin{tabular}{lcc}
\hline Componentes $\left(\mathrm{g} \cdot 100^{-1}\right)$ & Fécula & Polpa de laranja \\
\hline Umidade & 12,2 & 9,78 \\
Amido & 88,43 & - \\
Fibras totais & 0,15 & 85,31 \\
Fibra insolúvel & & 47,15 \\
Fibra solúvel & & 38,16 \\
Açúcares totais & 0,14 & 1,84 \\
Matéria graxa & 0,26 & 0,60 \\
Proteína & 0,07 & 0,7 \\
Cinzas & 0,1 & 1,7 \\
\hline
\end{tabular}


cinzas e acidez máxima (\% p/p) de 1,00 mL de NaOH N.100 g g $^{-1}$ (BRASIL, 1978).

A polpa cítrica mostrou elevada porcentagem de fibras, considerável teor de açúcares e cinzas. Contudo, os resultados obtidos diferiram dos observados por Céspedes, Chang e Bustos (2005) que encontraram 9,79\% de proteína, 2,43\% de lipídios, 2,66\% de cinzas, $74,87 \%$ de fibra alimentar total, $54,81 \%$ de fibra insolúvel e $20,06 \%$ de fibra solúvel na polpa de laranja. Larrea, Chang e Bustos (2005), analisando polpa cítrica desidratada, observaram um teor de $74,87 \%$ de fibras alimentares totais. Estes resultados, apesar de diferirem dos obtidos neste trabalho, confirmam que este resíduo da industrialização da laranja é importante fonte de fibra alimentar para produtos extrusados.

\subsection{Propriedades de pasta}

A gelatinização é o processo de transformação do amido granular em pasta viscoelástica. Com o aumento da temperatura, na presença de água, há rompimento dos grânulos, que se transformam em substância gelatinosa, um tanto opalescente, à qual se dá o nome de goma ou pasta de amido (FRANCO et al., 2001).

Os resultados obtidos na análise dos dados para os parâmetros de propriedades de pasta das misturas extrusadas estão apresentados na Tabela 4.

Ao realizar tratamento térmico por extrusão, o amido gelatiniza, absorve água a frio e, quanto maior o grau de gelatinização, maior será a capacidade de formar uma pasta, gel ou líquido viscoso à temperatura ambiente (EL-DASH; GONZALES; CIOL, 1984). O valor da viscosidade inicial se eleva com a prévia gelatinização da amostra e decresce quando os grânulos de amido se rompem e são despolimerizados durante a cocção (NEWPORT SCIENTIFIC, 1998).

As viscosidades iniciais dos produtos extrusados variaram de 6,08 a 36,25 RVU (Rapid Visco Units). Dentre os parâmetros do modelo, ocorreu influência significativa do teor de fibras na mistura sobre a Viscosidade Inicial (VI).

A Figura 1 mostra que a viscosidade inicial dos produtos foi mais alta quando as porcentagens de fibra nas misturas eram maiores, o que pode ser devido à absorção de água pelas fibras e também por uma menor degradação da estrutura amilácea na presença de fibras.

Durante o ciclo de aquecimento até $95^{\circ} \mathrm{C}$, ocorre o intumescimento e gelatinização dos grânulos de amido, atingindo o pico máximo de viscosidade. No processo de extrusão, dependendo das condições, o tratamento térmico pode destruir a estrutura cristalina do amido, de tal forma que, no ciclo de aquecimento, o viscoamilograma apresenta ausência de pico e valores muito baixos de viscosidade.

Analisando-se os coeficientes de regressão (Tabela 4), observou-se que os teores de umidade e fibras nas misturas afetaram significativamente esta variável. Os valores observados para o pico de viscosidade variaram de 6,33 a 38,50 RVU, sendo que nas condições de baixa umidade e elevada porcentagem de fibras e também em seus inversos ocorreram os maiores picos de viscosidade (Figura 2).

Whalen et al. (1997), avaliando as condições operacionais na extrusão de misturas de farinhas de arroz, trigo e milho, com a temperatura variando de 160 a $190^{\circ} \mathrm{C}$ e a rotação mantida em 200 rpm, observaram que a diminuição da umidade de 29 para $15 \%$ resultou em redução significativa do pico de viscosidade das amostras.

A quebra de viscosidade representa a diferença entre o pico de viscosidade e o menor valor de viscosidade após o pico no perfil amilográfico. Através desta propriedade é possível avaliar a estabilidade do produto em altas temperaturas, sob agitação mecânica.

A quebra de viscosidade dos produtos extrusados variou de 5,08 a 33,58 RVU. Os baixos valores de quebra de viscosidade devem-se ao fato de que, devido à degradação da fração amilácea, não ocorreram picos significativos de viscosidade. Foi observado efeito significativo dos teores de umidade e fibras sobre esta propriedade de pasta nas misturas extrusadas.

A Figura 3 mostra que, de acordo com o modelo ajustado nas condições de elevada umidade e teor de fibras na mistura, ocorrem

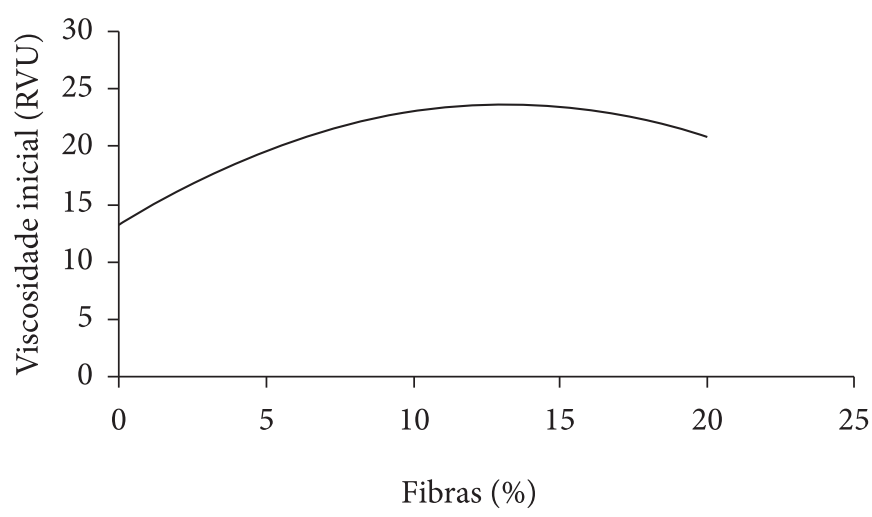

Figura 1. Efeito do teor de fibras (\%) na mistura de fécula de mandioca e polpa de laranja sobre a viscosidade dos produtos extrusados, com $18 \%$ de umidade na mistura e temperatura de $95^{\circ} \mathrm{C}$.

Tabela 4. Modelos matemáticos para as propriedades de pasta das misturas extrusadas.

\begin{tabular}{|c|c|c|c|c|}
\hline & Modelo codificado & $\mathrm{R}^{2}$ & $\mathrm{~F}_{\text {calculado }}$ & $\mathrm{F}_{\text {tabelado }}$ \\
\hline VI & $y=18,79+5,254 . x_{3}$ & 0,2502 & 6,01 & 4,41 \\
\hline PV & $y=15,3+3,49 \cdot x_{2}+5,10 \cdot x_{3}+5,83 \cdot x_{5}+3,09 \cdot x_{6}-4,94 \cdot x_{9}$ & 0,7323 & 7,66 & 2,96 \\
\hline QV & $y=14,21+4,41 \cdot x_{3}+4,78 \cdot x_{5}$ & 0,4274 & 6,34 & 3,59 \\
\hline VF & $\mathrm{y}=8,54+2,54 \cdot \mathrm{x}_{5}$ & 0,4159 & 12,82 & 4,41 \\
\hline TR & $y=5,16-1,17 \cdot x_{1}+1,77 \cdot x_{5}-1,36 \cdot x_{8}$ & 0,6883 & 11,78 & 3,24 \\
\hline
\end{tabular}




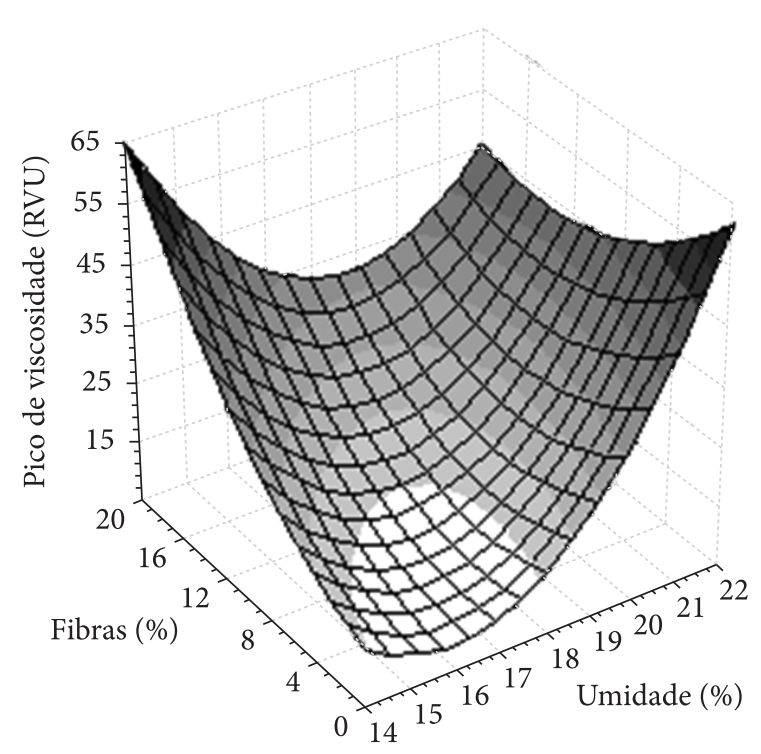

$$
\begin{array}{llll}
\square 14,648 & \square 19,648 & \square 24,706 & \square 29,735 \\
\square 34,765 & \square 39,794 & \square 44,823 & \square 49,852 \\
\square 54,881 & \square 59,910 & \square \text { Above } &
\end{array}
$$

Figura 2. Efeito dos teores de umidade (\%) e fibras (\%) na mistura de fécula de mandioca e polpa de laranja sobre o pico de viscosidade (RVU) dos produtos extrusados, sob temperatura de $95^{\circ} \mathrm{C}$.

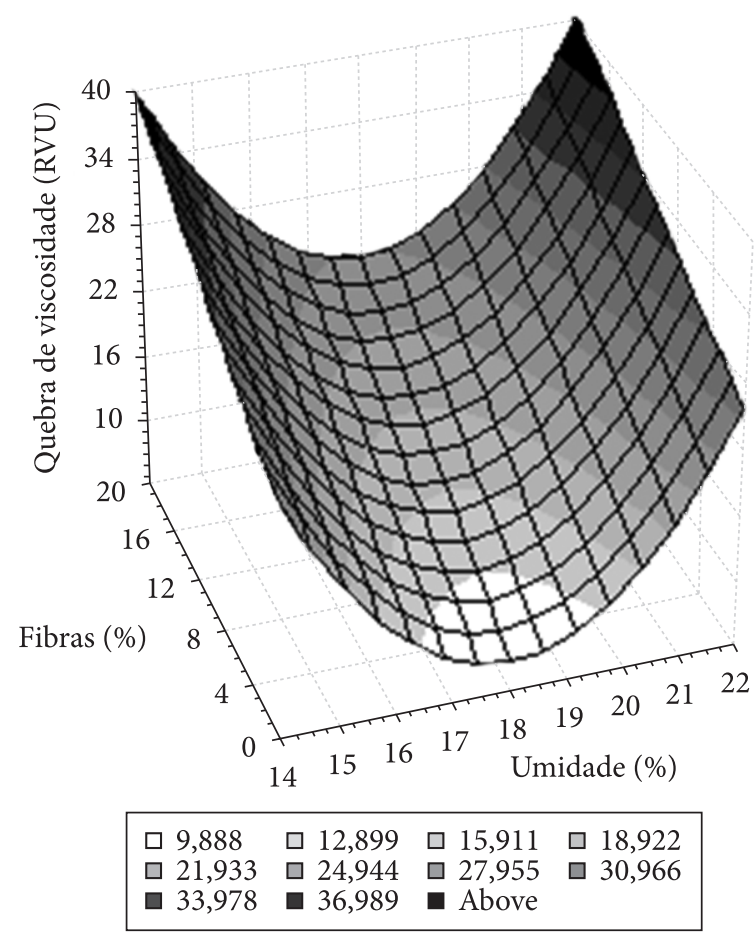

Figura 3. Efeito dos teores de umidade (\%) e fibras (\%) na mistura de fécula de mandioca e polpa de laranja sobre a quebra de viscosidade (RVU) dos produtos extrusados, sob temperatura de $95^{\circ} \mathrm{C}$.

as maiores quebras de viscosidade nas misturas extrusadas. Este comportamento também é observado na condição de baixa umidade e elevada concentração de fibras. Já os menores valores de quebra de viscosidade ocorrem nas condições de umidade mais elevada e baixo teor de fibras (Figura 3).

Bhattacharya, Sudha e Rahim(1999), ao estudar o efeito de parâmetros de extrusão em misturas de farinha de batata e de trigo, observaram menores valores de Quebra de Viscosidade (QV) em baixa umidade (15,5\%) e a elevação da umidade para $20,7 \%$ proporcionou aumento significativo nos valores de QV. Segundo os autores, os elevados teores de umidade na matériaprima poderiam estar agindo como lubrificantes, reduzindo a viscosidade de fusão durante a extrusão e elevando os valores de quebra de viscosidade.

A viscosidade final é uma característica que, em produtos extrusados, vai depender das modificações que ocorrem nas estruturas do grânulo de amido e dos outros componentes não amiláceos durante o processamento (EL-DASH, 1982).

A análise dos coeficientes de regressão para a viscosidade final mostrou efeito significativo da umidade sobre esta propriedade das misturas após a extrusão. Os valores de viscosidade final observados foram bastante baixos $(4,83$ a $17,58 \mathrm{RVU})$, valores estes inferiores aos observados por Borba (2005) que, estudando o efeito da temperatura de extrusão (86 a $154^{\circ} \mathrm{C}$ ), umidade das amostras (13 a 23\%) e rotação da rosca $(160$ a $260 \mathrm{rpm})$ sobre as propriedades de pasta de farinha de batata-doce extrusada, observou valores de 25 a 43 RVU, com efeito da rotação da rosca sobre a viscosidade final.

A Figura 4 mostra que, de acordo com o modelo ajustado, os menores valores de viscosidade final são observados nas condições intermediárias de umidade, teor de fibras e temperatura de extrusão. Nas condições de baixa umidade, o teor de fibras pode agir como barreira na degradação do amido, sendo este efeito menos pronunciado com o aumento da umidade até um ponto em que a umidade pode agir como lubrificante, interferindo na degradação dos componentes da mistura.

Bhattacharya, Sudha e Rahim(1999), avaliando o efeito da umidade inicial das amostras de misturas de farinha de trigo e batata sobre o comportamento de pasta de produtos extrusados, utilizando o Rapid Visco Analyser (RVA), não observaram no resfriamento aumento acentuado da viscosidade aparente, indicando degradação da fração amilácea durante a extrusão, resultando, assim, em aumento insignificante da viscosidade final a $50{ }^{\circ} \mathrm{C}$. Da mesma forma que neste experimento, os maiores valores de VF encontrados pelos autores foram nas condições de elevada umidade.

A retrogradação do amido ocorre por efeito da recristalização das moléculas de amilose e amilopectina, decorrente do agrupamento das partes lineares das moléculas de amido através da formação de novas ligações de hidrogênio, resultando na formação de precipitados e/ou géis (GUTKOSKI, 2000).

Os valores da tendência à retrogradação dos produtos extrusados variaram de 3,58 a 12,00 RVU. Uma característica marcante de produtos extrusados é a de não apresentar aumento de viscosidade com o abaixamento da temperatura de 95 para $50{ }^{\circ} \mathrm{C}$. A análise dos coeficientes de regressão mostrou o efeito 


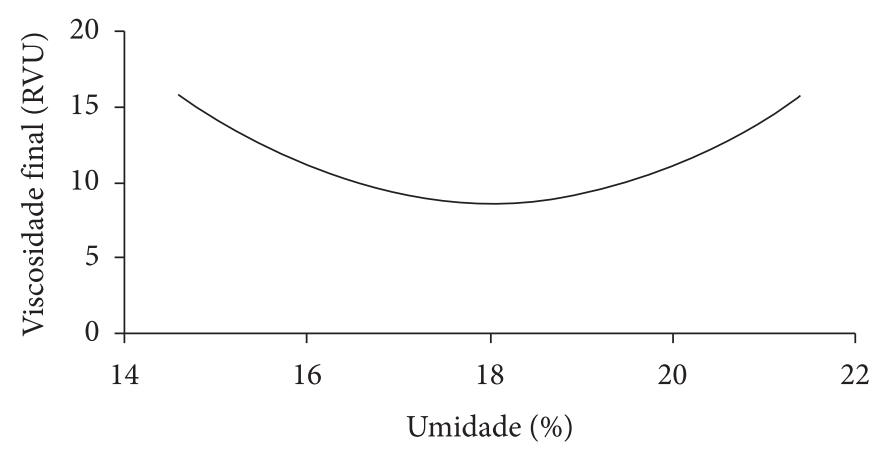

Figura 4. Efeito do teor de umidade (\%) na mistura de fécula de mandioca e polpa de laranja sobre a viscosidade dos produtos extrusados, com $10 \%$ de fibras na mistura e temperatura de $95^{\circ} \mathrm{C}$.

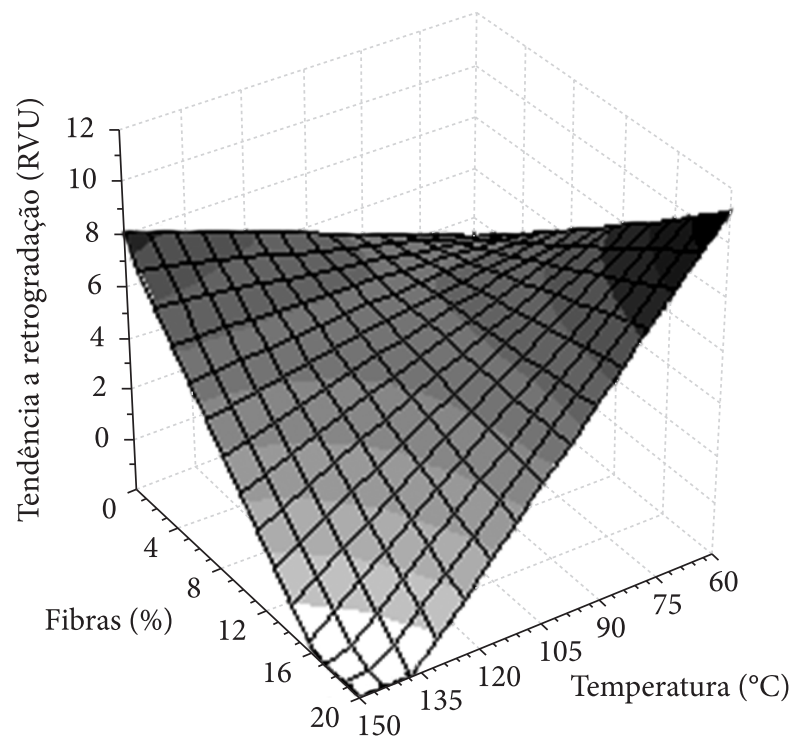

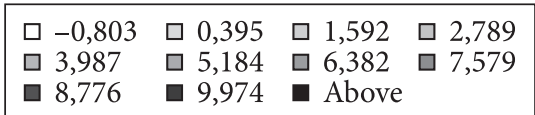

Figura 5. Efeito do teor de fibras (\%) na mistura de fécula de mandioca e polpa de laranja e da temperatura de extrusão sobre a tendência à retrogradação dos produtos extrusados, com $18 \%$ de umidade na mistura.

significativo da temperatura de extrusão, da umidade e da interação temperatura e fibras.

Através da superfície de resposta obtida a partir do modelo ajustado para a Tendência à Retrogradação (TR) das misturas extrusadas, observa-se que os maiores valores de TR são obtidos nas condições de elevada temperatura e teor mais elevado de fibras e, também, em baixa temperatura e umidade, com teor médio de fibras (Figuras 5 e 6).

Baixas tendências à retrogradação em produtos extrusados indicam severidade dos tratamentos, com a degradação dos polímeros, rompimento das estruturas moleculares e redução da capacidade de recristalização.

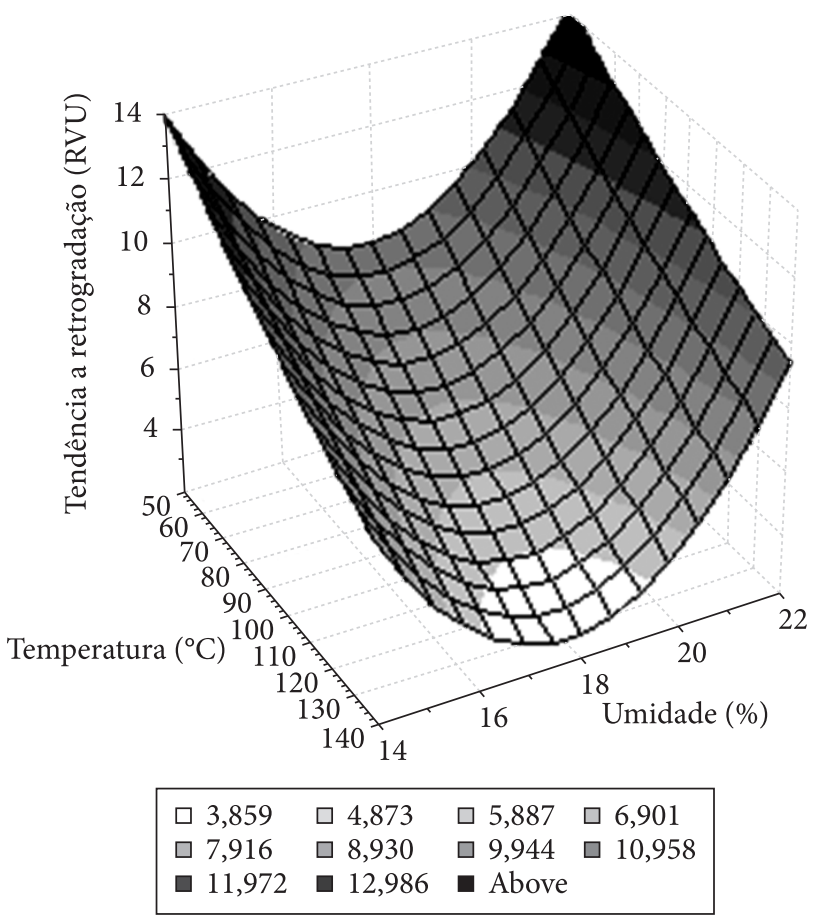

Figura 6. Efeito do teor de umidade (\%) na mistura de fécula de mandioca e polpa de laranja e da temperatura de extrusão sobre a tendência à retrogradação dos produtos extrusados, com $10 \%$ de fibras na mistura.

Larrea, Chang e Bustos (2005) observaram alterações significativas nos teores de fibra solúvel e insolúvel de polpa de laranja extrusada e concluíram que condições de elevada temperatura e baixa umidade ou nas condições de elevada umidade e temperatura sob longo tempo de residência (baixa rotação da rosca) ocorre uma diminuição da fibra insolúvel e aumento da solúvel. Este efeito, segundo os autores, poderia ser resultado do rompimento de ligações covalentes e não covalentes entre carboidratos e proteínas associados às fibras, resultando em pequenos fragmentos moleculares, os quais poderiam ser mais solúveis.

Portanto, nas condições de elevada temperatura e umidade pode ter ocorrido a degradação da estrutura amilácea e alterações estruturais nas fibras levando a baixos valores de tendência à retrogradação.

\section{Conclusões}

A partir dos resultados obtidos foi possível observar que o teor de fibras foi a variável mais importante, seguida pelo teor de umidade das misturas, interferindo nas propriedades de pasta das misturas de fécula de mandioca e polpa cítrica.

Tendo em vista a possibilidade de utilização desta mistura em produtos instantâneos ricos em fibras, as condições de baixa umidade, teor de fibras mediano $(10 \%)$ e temperaturas mais amenas $\left(<95^{\circ} \mathrm{C}\right)$ promovem menor degradação dos componentes da mistura, permitindo a obtenção de produtos com propriedades de pasta interessantes para esta aplicação. 


\section{Agradecimentos}

Os autores agradecem ao CNPq e à PRAD/UNESP os auxílios financeiros concedidos.

\section{Referências bibliográficas}

AMERICAN ASSOCIATION OF CEREAL CHEMISTS - AACC. Approved methods of the American Association of Cereal Chemists. 7. ed. St. Paul, 1983.

AREAS, M. A. Estudo dos efeitos da polpa de laranja sobre parâmetros fisiológicos, nutricionais, bioquímicos e morfológicos em ratos normais e diabéticos. $158 \mathrm{f}$. Tese (Doutorado em Ciência dos Alimentos)-Faculdade de Engenharia de Alimentos, Universidade Estadual de Campinas, Campinas, 1994.

ASCHERI, D. P. R. et al. Efeito da extrusão sobre a adsorção de água de farinhas mistas pré-gelatinizadas de arroz e bagaço de jabuticaba. Ciência e Tecnologia Alimentos, v. 26, n. 2, p. 325-335, 2006.

ASP, N. G. et al. Rapid enzymatic assay of insoluble and soluble dietary fiber. Journal of Agricultural and Food Chemistry, v. 31, n. 3, p. 476-482, 1983.

ASSOCIAÇÃO BRASILEIRA DOS EXPORTADORES DE CÍTRICOS - ABECITRUS. Subprodutos da laranja. Disponível em:<http:// www.abecitrus.com.br>. Acesso em: 27 jan. 2009.

BHATTACHARYA, S.; SUDHA, M.; RAHIM, A. Pasting characteristics of an extruded blend of potato and wheat flours. Journal of Food Engineering, v. 40, p. 107-111, 1999.

BOEKEL, S.; PUMAR, M.; FREITAS, M. C. Albedo e polpa de laranjapêra (Citrus sinensis, Osbeck) como fonte de fibra alimentar cítrica. In: CONGRESSO BRASILEIRO DE CIÊNCIAS E TECNOLOGIA DE ALIMENTOS, 17., 2002, Porto Alegre.

BORBA, A. M. Efeito de alguns parâmetros operacionais nas características físicas, físico-químicas e funcionais de extrusados da farinha de batata-doce (Ipomoea batatas). $72 \mathrm{f}$. Dissertação (Mestrado em Ciências)-Escola Superior de Agricultura Luiz de Queiroz, Universidade de São Paulo, Piracicaba, 2005.

BRASIL. Decreto no 12.486 , de 20 de outubro de 1978. Normas técnicas especiais relativas a alimentos e bebidas. Diário Oficial do Estado de São Paulo, 21 de outubro de 1978.

CÉSPEDES, M. A. L.; CHANG, Y. K.; BUSTOS, F. M. Some functional properties of extruded orange pulp and its effect on the quality of cookies. LWT-Food Science and Technology, v. 38, p. 213-220, 2005.

CHANG, Y. K. et al. Influence of extrusion condition on cassava starch and soybean protein concentrate blends. Acta Alimentaria, v. 30, n. 2, p. 189-203, 2001.
CHAU, C. F.; HUANG, Y. L. Comparison of the chemical composition and physicochemical properties of different fibers prepared from the peel of Citrus sinensis L. cv. Liucheng. Journal of Agriculture and Food Chemistry, v. 51, p. 2615-2618, 2003.

CHEFTEL, J. C. Nutritional effects of extrusion cooking. Food Chemistry, v. 20, n. 3, p. 263-283, 1986.

COCHRAN, W. G.; COX, G. M. Experimental Designs. 2. ed. New York: John Wiley \& Sons, 1957. 611 p.

EL-DASH, A. A. Aplication and control of thermoplastic extrusion of cereals for food and industrial uses, In: POMERANZ, Y.; MUNCH, L. Cereals a renewable resource: theory and pratice. St. Paul: AACC, 1982. p. 165-216.

EL-DASH, A. A.; GONZALES, R.; CIOL, M. Response surface methodology in the control of termoplastic extrusion of starch. In: JOWITT, R. (Ed.). Extrusion cooking technology. London: Elsevier Applied Science Publishers, 1984. p. 51-74.

FRANCO, C. M. L. et al. Propriedades do amido. In: CEREDA, M. P. (Coord.). Propriedades gerais do amido. Campinas: Fundação Cargill, 2001. p. 141-184.

GUTKOSKI L. C. Extrusão de produtos de aveia. In: GUTKOSKI, L. C.; PEDÓ, I. Aveia: composição química, valor nutricional e processamento. São Paulo: Varela, 2000. p. 169-103.

GUY, R. Raw materials for extrusion cooking. In: GUY, R. Extrusion cooking. Boca Raton: Woodhead Publishing, 2001. cap. 2, p. 5-28.

INSTITUTO BRASILEIRO DE GEOGRAFIA E ESTATÍSTICA - IBGE. 2006. Disponível em: www.ibge.gov.br.

LARREA, M. A.; CHANG, Y. K.; BUSTOS, F. M. Effect of some operational extrusion parametres on the constituints of orange pulp. Food Chemistry, v. 89, p. 301-308, 2005.

LEONEL, M.; CEREDA, M. P.; ROAU, X. Aproveitamento do resíduo da produção de etanol a partir de farelo de mandioca, como fonte de fibras dietéticas. Ciência e Tecnologia de Alimentos, v. 19, n. 2, p. 241-245, 1999.

MENDONÇA, S.; GROSSMAN, M. V. E.; VERBÉ, R. Corn bran as a fibre source in expanded snacks. Lebensmittel-Wissenschaft und -Technologie, v. 33, p. 2-8, 2000.

NEWPORT SCIENTIFIC. Operation manual series 4: instructions manual. Warriedwood, 1998. 123 p.

SANTANA, M. F. S. Caracterização físico-química de fibra alimentar de laranja e maracujá. 168 p. Tese (Doutorado em Engenharia de Alimentos)-Faculdade de Engenharia de Alimentos, Universidade Estadual de Campinas, Campinas, 2005.

WHALEN, P. J. et al. Measurement of extrusion effects by viscosity profile using rapid viscoanalyser. Cereal Foods World, v. 42, n. 6 , p. 469-475, 1997. 